\title{
A NEWSVENDOR FRAMEWORK OF EXCHANGE RATE RISK WITH UNIFORMLY DISTRIBUTED EXCHANGE RATE ERROR
}

\author{
Sanjay Patel ${ }^{1}$, Ravi Gor ${ }^{2}$ \\ ${ }^{I}$ Mathematics Department, St. Xavier's College, Ahmedabad, India \\ ${ }^{2}$ Dr. Babasaheb Ambedkar Open University, Ahmedabad, India
}

\begin{abstract}
In a global supply chain consisting of one retailer and one manufacturer, both from different countries when there is a time lag between the payments made while placing the order and the time when the order is realized, risk in the form of the exchange rate fluctuation affects the optimal pricing and order quantity decisions. We elaborate uniformly distributed exchange rate fluctuation when the retailer or manufacturer undertakes to share the exchange rate risk and the demand error is modelled in the additive form in the news vendor framework. We also have compared the exchange rate effect with the generalized beta distribution error in the model given in Arcelus, Gor and Srinivasan [1]. This is accomplished by numerical example using maple software to compare the two scenarios of the retailer and manufacturer.
\end{abstract}

Keywords: Transaction Exposure, Exchange Rate Error, Newsvendor Problem, Optimal Pricing and Quantity, Uniform Distribution, Generalized Beta Distribution.

\section{INTRODUCTION}

Suppose two different countries having different currencies are into a business. When the exchange rate between the two currencies gets an exposure to unexpected changes, there exists a financial risk and this risk is known as foreign exchange risk (or exchange rate risk). A transaction exposure arises only when there exists a time lag between the time of the financial obligation has been incurred and the time its due to be settled. This is because of the purchase price to buyer/ retailer on the settlement day may differ from that when it was incurred, if the debt is denominated in the manufacturer currency. Arcelus, Gor and Srinivasan [1] have developed a mathematical model in news vendor framework to find optimum ordering and pricing policies for retailer/manufacturer, when the foreign exchange rate between the two countries doing the business, faces transaction exposure. The complete derivation of optimum policies and expected profit of the foreign exchange model for additive demand error is given in Sanjay Patel, Ravi Gor [2]. Our main contribution in this paper is to explain the effect of uniform distribution in the exchange rate error under the linear demand with additive error in news vendor setting. The effect of uniform error is also compared with the generalized beta distribution error in the exchange rate.

\section{LITERATURE REVIEW}

This paper fundamentally follows the model of Arcelus, Gor and Shrinivasan[1]. Cases of transaction exposure when a firm has an accounts receivable or payable denominated in a foreign currency has been reported in Goel [3]. The nature of global trade is that either the buyer or the seller has to bear what is commonly known in international finance as transaction exposure, Eitemann et al.[4], Shubita et al.[5]. The very important newsvendor framework introduced by
Petruzzi and Dada [6] and the price dependent demand forms in the additive and multiplicative error structures by Mills[7] and Karlin and Carr[8] have been used. The derivation of the expected profit and optimal policies, when demand is linear, are given in Sanjay Patel, Ravi Gor [2] and for multiplicative demand error in Sanjay Patel and Ravi Gor[9]. We have also developed more general hybrid model for additive and multiplicative demand error Sanjay patel and Ravi Gor[10].

\section{EXCHANGE RATE RISK MODEL OUTLINE}

Suppose a retailer wants to order $\mathrm{q}$ units from a foreign manufacturer of a certain product. The retailer does not know the demand (D) of the product, which is uncertain. But it partly depends upon the price $(p)$ and partly random. In this paper we take the price dependent demand with additive error which can be defined as $D(p, \in)=g(p)+\in$, where $\in$ is the additive error in the demand and it follows some distribution(say $f(\epsilon)$ ) with mean $\mu$ in some interval $[\mathrm{A}, \mathrm{B}]$ and $\mathrm{g}(p)$ is the deterministic demand. [Generally $\mathrm{g}(\mathrm{p})$ is taken as decreasing linear function of $p$ say, $g(p)=a-b p$ in additive demand error case with the restrictions $a, b>0]$.

Let the exchange rate be ' $r$ ' in the retailer currency when the order is placed. Let $w$ be the cost of one unit of the product in the manufacturer currency. If the buyer pays immediately then he has to pay wr per unit of the product in his currency.

Suppose there is a time lag (some fixed period) between the order is placed and the amount is paid for the product when it is acquired by the retailer. Thus there exists transaction 
exposure risk, since the exchange rate (r) may get fluctuate. So the buyer has to pay more or less according to the existing rate at the time of the arrival of the product. Generally the fluctuation in the exchange rate $r$ is very small and random. We model the future exchange rate(FER) as, $\mathrm{FER}=$ current exchange rate + fluctuation in the exchange rate. The fluctuation in the exchange rate is always some percentage of $r$, hence we can take the $F E R=r+r \in_{r}$ $=r\left(1+\epsilon_{\mathrm{r}}\right)$. Where $\epsilon_{\mathrm{r}}$ is also a random variable together with the random variable $\mathrm{D}$. We assume that $\epsilon_{\mathrm{r}}$ lies in $[-\mathrm{a}, \mathrm{a}]$. Here $0<\mathrm{a}<1$. The fluctuation $\in_{\mathrm{r}}$ is unknown but its distribution is known say $\psi\left(\in_{\mathrm{r}}\right)$. In this paper we consider uniform distribution for $\epsilon_{\mathrm{r}}$ with support [a,b] i.e. $\psi(y)=\frac{1}{b-a}$. The expected value of the fluctuation in the exchange rate error is therefore $E(y)=\frac{a+b}{2}$.

If the fluctuation $\in_{\mathrm{r}}$ is positive buyer has to pay more and if it is negative seller will get less. So the question arises here is that who will bare the exchange rate risk? Buyer/retailer OR seller/manufacturer? In this paper we discuss the two situations under the additive demand error. In each case the retailer's optimal policy is to determine the optimum $\operatorname{order}(q)$ and selling price(p) of the product so that his expected profit is maximum. At the same time we obtain the manufacturer's optimal policies as well.

\subsection{Assumptions and Notations}

The following assumptions are made in the foreign exchange transaction exposure model:

(i) The standard newsvendor problem assumptions apply.

(ii) The global supply chain consists of single retailersingle manufacturer.

(iii) The error in demand is additive.

(iv) Only one of the two-retailer or manufacturer- bears the exchange rate risk.

The following notations are used in the paper:

$\mathrm{q}=$ order quantity

$\mathrm{p}=$ selling price per unit

$\mathrm{D}=$ demand of the product $=$ no. of units required

$\epsilon=$ demand error= randomness in the demand.

$v=$ salvage value per unit

$\mathrm{s}=$ penalty cost per unit for shortage

$\mathrm{c}=$ cost of manufacturing per unit for manufacturer

$\mathrm{W}_{\mathrm{r}}=$ purchase cost for retailer

$\epsilon_{\mathrm{r}}=$ the exchange rate fluctuation= exchange rate error= randomness in exchange rate

$\Pi=$ profit function.

\subsection{The Two Scenarios}

\section{Case-1: Retailer bears the exchange Rate Risk}

In the case- 1 we assume that the retailer bears the exchange rate risk and manufacturer does not. Thus the manufacturer will get $\mathrm{w}$ per unit at any point of time and the buyer will have to pay according to the existing exchange rate. So the buyer will be paying $\operatorname{wr}\left(1+\epsilon_{\mathrm{r}}\right)$ per unit, on the settlement day or when the product is acquired by him. This amount in terms of manufacturer currency is $\mathrm{wr}\left(1+\epsilon_{\mathrm{r}}\right) / \mathrm{r}=\mathrm{w}\left(1+\epsilon_{\mathrm{r}}\right)=\mathrm{W}_{\mathrm{r}}$ (say). Thus $\mathrm{w}_{\mathrm{r}}$ is the purchase cost to buyer in seller's currency.

Now the retailer/ buyer will choose the selling price $p$ and the orderquantity $q$ so as to maximize his expected profit. The profit function for the retailer is given by,

$\Pi(p, q)=[$ revenue from $q$ items] - [expenses for the $q$ items]

$\Pi(p, q)=\left\{\begin{array}{l}{[p D+v(q-D)]-\left[q w_{r}\right] \text { if } D \leq q \text { (overstocking) }} \\ {[p q]-\left[s(D-q)+q w_{r}\right] \text { if } D>q \quad \text { (shortage) }}\end{array}\right.$

Note that all the parameters $p, v, s, w_{r}$ are taken in manufacturer's currency and the salvage value $v$ is taken as an income from the disposal of each of the $q$-D leftover.

Since the demand, $D(p, \in)=g(p)+\in$ the retailer's profit function (1) for ordering $q$ units and keeping selling price $p$ is given by,

$$
\Pi(p, q)=\left\{\begin{array}{c}
p(g(p)+\in)+v(q-g(p)-\epsilon)-q w_{r} \text { if } D \leq q \\
p q-s(g(p)-q+\in)-q w_{r} \text { if } D>q
\end{array}\right.
$$

Put $g(p)=g$ and define $z=q-g(p)=q-g$ i.e. $q=z+g$, for the additive demand error.

Now $D \leq q \Leftrightarrow g+\in \leq q \Leftrightarrow \in \leq q-g \Leftrightarrow \in \leq z$ andsimilarly $D>q \Leftrightarrow \in>z$. Thus we have,

$$
\Pi(\mathrm{z}, p)=\left\{\begin{array}{l}
p(g+\in)+v(\mathrm{z}-\in)-w_{r}(z+g) \text { if } \in \leq z \\
p(z+g)-s(\in-z)-w_{r}(z+g) \text { if } \in>z
\end{array}\right.
$$

The equation (2) describes the profit function for the retailer in the manufacturer currency. Note that the parameter $q$ is replaced by $z$. Now the retailer wants to find the optimal order quantity q say $\mathrm{q}^{*}$ and optimal price $\mathrm{p}=\mathrm{p}^{*}$ to maximize his expected profit. In order to do this he must find optimal values of the price $\mathrm{p}$ and the parameter $\mathrm{z}$, say $\mathrm{p}^{*}$ and $\mathrm{z}^{*}$ respectively which maximizes his expected profit so that he can determine the optimal order $\mathrm{q}^{*}=\mathrm{z}^{*}+\mathrm{g}\left(\mathrm{p}^{*}\right)$. The profit $\Pi$ is a function of the random variable $\in$ with support $[\mathrm{A}, \mathrm{B}]$. Thus the retailer's expected profit is given by,

$E[\Pi(z, p)]=\int_{A}^{B} \Pi(z, p) f(u) d u$.(Here we take $\in=u$ for simplicity in (2)). Then we get,

$E[\Pi(z, p)]=\int_{A}^{Z}\left[p(g+u)+v(\mathrm{z}-u)-w_{r}(z+g)\right] f(u) d u$

$+\int_{z}^{B}\left[p(z+g)-s(u-z)-w_{r}(z+g)\right] f(u) d u$

Define $\Lambda(z)=\int_{A}^{z}(z-u) f(u) d u$ [expected leftovers] and 
$\Phi(z)=\int_{Z}^{B}(\mathrm{u}-z) f(u) d u \quad$ [expected shortages]

Then the expected profit of the retailer as a function of $z$ and pis given by,

$E[\Pi(z, p)]=\left(p-w_{r}\right)(g+\mu)-\left(w_{r}-v\right) \Lambda-\left(p+s-w_{r}\right) \Phi(4)$

as derived inSanjay Patel and Ravi Gor[2].

Where $\mu=\int_{A}^{B} u f(u) d u$ in the equation (4) and it gives

the expectedvalue of the randomness $u$ in the demand $\mathrm{D}$.

We use Whitin's method [11] to maximize the expected profit function. In this method first we keep $p$ fixed in (4) and use the second order optimality conditions $\frac{\partial E}{\partial z}=0$ and $\frac{\partial^{2} E}{\partial z^{2}}<0$ to find the optimum value of $z^{*}$ as a function of $p$.

Then we substitute the value of $z^{*}$ in the expected profit (4) so that it becomes a function of $p$ and hence the optimal $\mathrm{p}^{*}$ can also be obtained. The authors have already derived the optimal policies given below, in Sanjay Patel and Ravi Gor [2].

$$
z^{*}=F^{-1}\left(\frac{p+s-w_{r}}{p+s-v}\right)
$$

Where $F(z)=\int_{A}^{z} f(u) d u$ is the CDF.

This $\mathrm{z}^{*}$ gives the optimum solution for maximum profit as a function of $p$.Now substitute this $z^{*}$ in $E[\Pi(z, p)]$ and obtain optimum $\mathrm{p}^{*}$ using the second order optimality criteria.

Hence the retailer's optimal order $\mathrm{q}=\mathrm{q}^{*}$ is given by,

$$
q^{*}=g\left(p^{*}\right)+z^{*}=g\left(p^{*}\right)+F^{-1}\left(\frac{p^{*}+s-w_{r}}{p^{*}+s-v}\right)
$$

Also the manufacturer's profit when the buyer bears the risk is [(selling price of seller)-(cost of purchase to seller)] $\times$ no. of units sold, $\Pi_{m}=(w-c) q^{*}$.

\section{Case-2: Manufacturer bears the exchange Rate Risk}

In the case-2 we assume that the manufacturer bears the exchange rate risk and retailer does not. Thus the retailer pays $w$ per unit in manufacturer's currency at any point of time and the manufacturer will get according to the existing exchange rate. So the manufacturer will be getting $w r /\left(r\left(1+\epsilon_{r}\right)\right)=w_{m}$ per unit on the settlement day in his currency. Now the retailer's profit function, his expected profit and optimal policies to get maximum expected profit can be obtained by replacing $w_{r}$ by $w$ in case- 1 . So we get the retailer's profit as,

$\Pi(p, q)=\left\{\begin{array}{l}{[p D+v(q-D)]-[q w] \text { if } D \leq q \text { (overstocking) }} \\ {[p q]-[s(D-q)+q w] \text { if } D>q \text { (shortage) }}\end{array}\right.$
And his expected profit as,

$E[\Pi(z, p)]=(p-w)(g+\mu)-(w-v) \Lambda-(p+s-w) \Phi(9)$

The optimal value of $\mathrm{z}$ is given by $z^{*}=F^{-1}\left(\frac{p+s-w}{p+s-v}\right)$ and hence the optimum order quantity is,

$$
q^{*}=g\left(p^{*}\right)+z^{*}=g\left(p^{*}\right)+F^{-1}\left(\frac{p^{*}+s-w}{p^{*}+s-v}\right)
$$

Also the manufacturer's profit when the buyer bears the risk is $[$ (selling price of seller)-(cost of purchase to seller) $] \times$ no. of units sold. $\Pi_{m}=\left(w_{m}-c\right) q^{*}$.

\section{SENSITIVITY ANALYSIS}

We assume linear demand with additive demand error $u$ which follows the uniform distribution $f(u)$ with support $[\mathrm{A}, \mathrm{B}]$. Then we obtain the optimum policies and maximum expected profit of the retailer and manufacturer using MAPLE software when anyone of them bears the exchange rate risk. We compute the optimum values by using uniform

distribution $\psi\left(\in_{r}\right)$ in the exchange rate error $\epsilon_{r}$ with support $[-0.1,0.1]$.In case- 1 and case- 2 we also compare it with the policies obtained by Arcelus, Gor, Shrinivasan. [1],for the generalized beta distribution in the exchange rate error for each of the case positive, negative and symmetrical beta distribution.Recall the uniform probability density function is $f(x, a, b)=\frac{1}{b-a}, a \leq x \leq b$ with mean $\mu=\frac{a+b}{2}$ and

standard deviation $\sigma=\frac{1}{\sqrt{12}}(b-a)$. And the four parameter beta density function is given by,

$$
f(y / a, b, \alpha, \beta)=\frac{(y-a)^{\alpha-1}(b-y)^{\beta-1}}{B(\alpha, \beta)(b-a)^{\alpha+\beta-1}} \text { where }
$$

$a \leq y \leq b, \alpha, \beta>0$ and its transformation in the standard beta distribution by taking $y=a+(b-a) x$ is given by $f(x / 0,1, \alpha, \beta)=\frac{x^{\alpha-1}(1-x)^{\beta-1}}{B(\alpha, \beta)}$ where $0 \leq x \leq 1, \alpha, \beta>0$ and $B(\alpha, \beta)=\int_{0}^{1} t^{1-\alpha}(1-t)^{1-\beta} d t$.

We assume the following parameter values:

Demand support $=[\mathrm{A}, \mathrm{B}]=[-3500,1500]$

Mean Demand $=\mu=\frac{A+B}{2}=-1000$

Linear Demand $g(p)=a-b p, a=100000, b=1500$

$v=$ Salvage value $=10$

$\mathrm{s}=$ Penalty cost $=5$

$\mathrm{c}=$ cost of manufacturing per unit for manufacturer $=20$

$\mathrm{r}=$ current exchange rate $=45$

The following computation in case- 1 and case- 2 is done using Maple software. 


\begin{tabular}{|c|c|c|c|c|c|c|}
\hline \multicolumn{7}{|c|}{ Case-1 Retailer Bears the risk } \\
\hline Distribution & $\begin{array}{l}\text { Parameters } \\
\text { of the dist. }\end{array}$ & $\mathrm{p}^{*}$ & $\mathrm{q}^{*}$ & $\begin{array}{l}\text { Seller's selling } \\
\text { price } w^{*}\end{array}$ & $\begin{array}{l}\text { Optimum exp. } \\
\text { profit of buyer }\end{array}$ & $\begin{array}{l}\text { Optimum } \\
\text { exp.profit of } \\
\text { seller }\end{array}$ \\
\hline Beta & $\alpha=1, \beta=3$ & 53.45 & 18047.19 & 43.82 & 195075 & 429886 \\
\hline Uniform & & 53.70 & 17640 & 42.13 & 185970 & 390548 \\
\hline \multirow[t]{2}{*}{ Variation $\%$} & & 0.467726848 & 2.256251527 & 3.856686445 & 4.667435602 & 9.150798119 \\
\hline & & $\uparrow$ & $\downarrow$ & $\downarrow$ & $\downarrow$ & $\downarrow$ \\
\hline Beta & $\alpha=3, \beta=1$ & 53.95 & 17234 & 40.61 & 177080 & 355344 \\
\hline Uniform & & 53.70 & 17640 & 42.13 & 185970 & 390548 \\
\hline \multirow[t]{2}{*}{ Variation $\%$} & & 0.46339203 & 17540 & 3.742920463 & 5.020329794 & 9.907019677 \\
\hline & & $\downarrow$ & $\uparrow$ & $\uparrow$ & $\uparrow$ & $\uparrow$ \\
\hline Beta & $\alpha=1, \beta=1$ & 53.70 & 17640 & 42.13 & 185970 & 390548 \\
\hline Uniform & & 53.70 & 17640 & 42.13 & 185970 & 390548 \\
\hline Variation $\%$ & & 0 & 0 & 0 & 0 & 0 \\
\hline Beta & $\alpha=2, \beta=5$ & 53.49 & 17989 & 43.56 & 193761 & 423989 \\
\hline Uniform & & 53.70 & 17640 & 42.13 & 185970 & 390548 \\
\hline \multirow[t]{2}{*}{ Variation $\% \% 5 \% \%$} & & 0.392596747 & 1.94007449 & 3.282828283 & 4.020933005 & 7.887232923 \\
\hline & & $\bar{\uparrow}$ & $\downarrow$ & $\downarrow$ & $\downarrow$ & $\downarrow$ \\
\hline Beta & $\alpha=5, \beta=2$ & 53.91 & 17292 & 40.82 & 178336 & 360.142 \\
\hline Uniform & & 53.70 & 17640 & 42.13 & 185970 & 390548 \\
\hline \multirow[t]{2}{*}{ Variation $\%$} & & 0.389538119 & 2.012491325 & 3.209211171 & 4.280683653 & 8.442780903 \\
\hline & & $\downarrow$ & $\bar{\uparrow}$ & $\bar{\uparrow}$ & $\uparrow$ & $\bar{\uparrow}$ \\
\hline
\end{tabular}

Case-2 Manufacturer Bears the risk

\begin{tabular}{|c|c|c|c|c|c|c|}
\hline Distribution & $\begin{array}{l}\text { Parameters of } \\
\text { the dist. }\end{array}$ & $\mathrm{p}^{*}$ & $\mathrm{q}^{*}$ & $\begin{array}{c}\text { Buyer's } \\
\text { purchase cost } \\
\mathrm{w}_{\mathrm{r}}{ }^{*}\end{array}$ & $\begin{array}{l}\text { Optimum exp. } \\
\text { profit of buyer }\end{array}$ & $\begin{array}{l}\text { Optimum exp. } \\
\text { profit of seller }\end{array}$ \\
\hline Beta & $\alpha=1, \beta=3$ & 53.45 & 18047 & 41.62 & 195075 & 429886 \\
\hline Uniform & & 53.70 & 17640 & 42.13 & 185970 & 390548 \\
\hline \multirow[t]{2}{*}{ Variation $\%$} & & 0.467726848 & 2.255222475 & 1.225372417 & 4.667435602 & 9.150798119 \\
\hline & & $\uparrow$ & $\downarrow$ & $\uparrow$ & $\downarrow$ & $\downarrow$ \\
\hline Beta & $\alpha=3, \beta=1$ & 53.95 & 17234 & 42.63 & 177080 & 355344 \\
\hline Uniform & & 53.70 & 17640 & 42.13 & 185970 & 390548 \\
\hline \multirow[t]{2}{*}{ Variation \% } & & 0.46339203 & 2.355808286 & 1.172882946 & 5.020329794 & 9.907019677 \\
\hline & & $\downarrow$ & $\uparrow$ & $\downarrow$ & $\uparrow$ & $\uparrow$ \\
\hline Beta & $\alpha=1, \beta=1$ & 53.70 & 17640 & 42.13 & 185970 & 390548 \\
\hline Uniform & & 53.70 & 17640 & 42.13 & 185970 & 390548 \\
\hline Variation $\%$ & & 0 & 0 & 0 & 0 & 0 \\
\hline Beta & $\alpha=2, \beta=5$ & 53.49 & 17989 & 41.70 & 193761 & 423989 \\
\hline Uniform & & 53.70 & 17640 & 42.13 & 185970 & 390548 \\
\hline \multirow[t]{2}{*}{ Variation $\%$} & & 0.392596747 & 1.94007449 & 1.03117506 & 4.020933005 & 7.887232923 \\
\hline & & $\uparrow$ & $\downarrow$ & $\uparrow$ & $\downarrow$ & $\downarrow$ \\
\hline Beta & $\alpha=5, \beta=2$ & 53.91 & 17292 & 42.56 & 178336 & 360142 \\
\hline Uniform & & 53.70 & 17640 & 42.13 & 185970 & 390548 \\
\hline \multirow[t]{2}{*}{ Variation $\%$} & & 0.389538 & 2.0124913 & 1.0103383 & 4.28068365 & 8.442780903 \\
\hline & & $\downarrow$ & $\uparrow$ & $\downarrow$ & $\uparrow$ & $\uparrow$ \\
\hline
\end{tabular}




\section{CONCLUSION}

We elaborate uniformly distributed exchange rate fluctuation when the retailer or manufacturer undertakes to share the exchange rate risk and the demand error is modelled in the additive form in the news vendor framework. We also have compared the exchange rate effect with the generalized beta distribution error which is evident from the above tables.

\section{REFERENCES}

[1]. Arcelus. F.J., Gor R. M., Srinivasan G., Foreign exchange transaction exposure in a newsvendor setting, European Journal of Operational Research, 227(2013) $552-557$

[2]. Sanjay Patel and Ravi Gor, Exchange rate risk sharing contract model, IOSR Journal of Mathematics(IOSRJM),e-ISSN: 2278-5728, p-ISSN: 2319765X., Volume11,Issue 2, Version-I (Mar-Apr. 2015),PP 47-52

[3]. Goel, M., 2012. Management of transaction exposure: a comparative analysis of MNCs in India. International Journal of Service Science, Management, Engineering and Technology 3, 37-54.

[4]. Eitemann, D.K., Stonehill, A.I., Moffett, M.H., 2010. Multinational Business Finance,12th ed. Prentice Hall, Boston.

[5]. Shubita, M.F., Harris, P., Malindretos, J., Bobb, L.M., 2011. Foreign exchange exposure: an overview. International Research Journal of Finance and Economics 78, 171-177.

[6]. Petruzzi, N.C., Dada, M., 1999. Pricing and the newsboy problem: a review with extensions. Operations Research 47, 183-194.

[7]. Mills, E.S., 1958. Uncertainty and price theory. Quarterly Journal of Economics 73, 116-130.

[8]. Karlin, S., Carr, C.R., 1962. Prices and optimal inventory policy. In: Arrow, K.J., Scarf, H. (Eds.), Studies in Applied Probability and Management Science. Stanford University Press, Palo Alto, CA, pp. 159-172.

[9]. Sanjay Patel and Ravi Gor, Transaction exposure risk modelled in a newsvendor framework under the multiplicative demand error, IOSR Journal of Mathematics(IOSR-JM),e-ISSN: 2278-5728, p-ISSN: 2319-765X., Volume11,Issue 2, Version-I (Mar-Apr. 2015),P 53-59

[10].Sanjay Patel and Ravi Gor. Foreign exchange transaction exposure within a newsvendor frame work under hybrid demand distribution- IOSR Journal of Mathematics(IOSR-JM),e-ISSN: 2278-5728, p-ISSN: 2319-765X ,Volume11,Issue 5, Version-I (Sep-Oct. 2015),P 51-58.

[11]. Whitin, T. M., 1955. Inventory control and price theory, Management Sci. 2 61-68.

\section{BIOGRAPHIES}

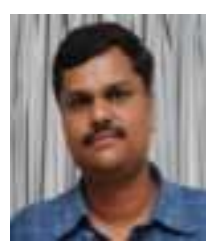

Prof. Sanjay Patel is an Associate professor of Mathematics at St. Xavier's College (Autonomous), Ahmedabad.

Email: swpatel3@gmail.com

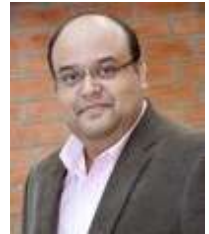

Dr. Ravi M. Gor is Director (academic) at Babasaheb Ambedkar Open University at Ahmedabad, Gujarat. Email: ravigor@hotmail.com 